Autores: Andrea Durval , Carolina de Jesus Couceiro de Freitas, Cássia Regina S.L. Callegon, Gabriela Nascimento de Azevedo Asaeda, Shirley Aparecida Lima e Wiviane Falasca Pereira

\title{
AUDITORIA DA QUALIDADE DOS REGISTROS DE ENFERMAGEM EM UM CENTRO DE REFERÊNCIA ESPECIALIZADO EM DEPENDÊNCIA QUÍMICA
}

\author{
Eixo Temático : Gestão em Saúde
}

Introdução: Centro de Referência de Álcool, Tabaco e Outras Drogas (Cratod), realiza parceria com a Associação Paulista para o Desenvolvimento da Medicina (SPDM), no centro de São Paulo, atualmente as instituições de saúde, tanto pública quanto privadas, estão em constante crescimento, exigindo uma maior qualidade do serviço prestado e cada vez mais preocupadas em otimizar seus custos. Neste contexto, a auditoria em saúde cresce e conquista seu lugar nas práticas cotidianas, através de ações que buscam a melhoria da qualidade.

Metodologia: A auditoria foi realizada através de uma pesquisa de caráter qualitativo e quantitativo descritivo. Para avaliação da qualidade dos registros de enfermagem, optou-se pela auditoria retrospectiva que estabelece mediante a analise da relação entre os critérios estabelecidos e os dados encontrados na revisão dos prontuário e observação direta de pacientes e prontuários, como ferramenta de gestão em saúde. Houve 106 observações no período de julho/2018 a novembro/2018.

Resultados: Foram apresentados em categorias, conforme critérios de avaliação estabelecidos e pela estatística descritiva para verificação do percentual de adequação dos registros. Os dados de identificação do paciente estavam adequados com $92 \%$ de registros nas pulseiras, leitos, acessos venosos periféricos e rótulos de soro. No quesito do registro de enfermagem através da realiza ção dos procedimentos, a anotação foi adequada em $83 \%$ dos prontuários auditados, porém o histórico, diagnóstico, evolução e a prescrição de enfermagem, obtiveram entre $57 \%$ a $60 \%$ de registros, portanto foram classificados como registros realizados de forma regular. Não houve dados que foram classificados como insuficiente (abaixo de 40\%).

Conclusão: Conclui-se que a auditoria, com a observação direta e a analise dos prontuários, permite identificar as falhas nos registros da equipe de enfermagem, e, desta forma, pode-se incentivar e promover a educação continuada dentro da instituição de saúde, atendendo as demandas dos profissionais, visando melhoria da qualidade dos registros da enfermagem e a constante busca da segurança do paciente.
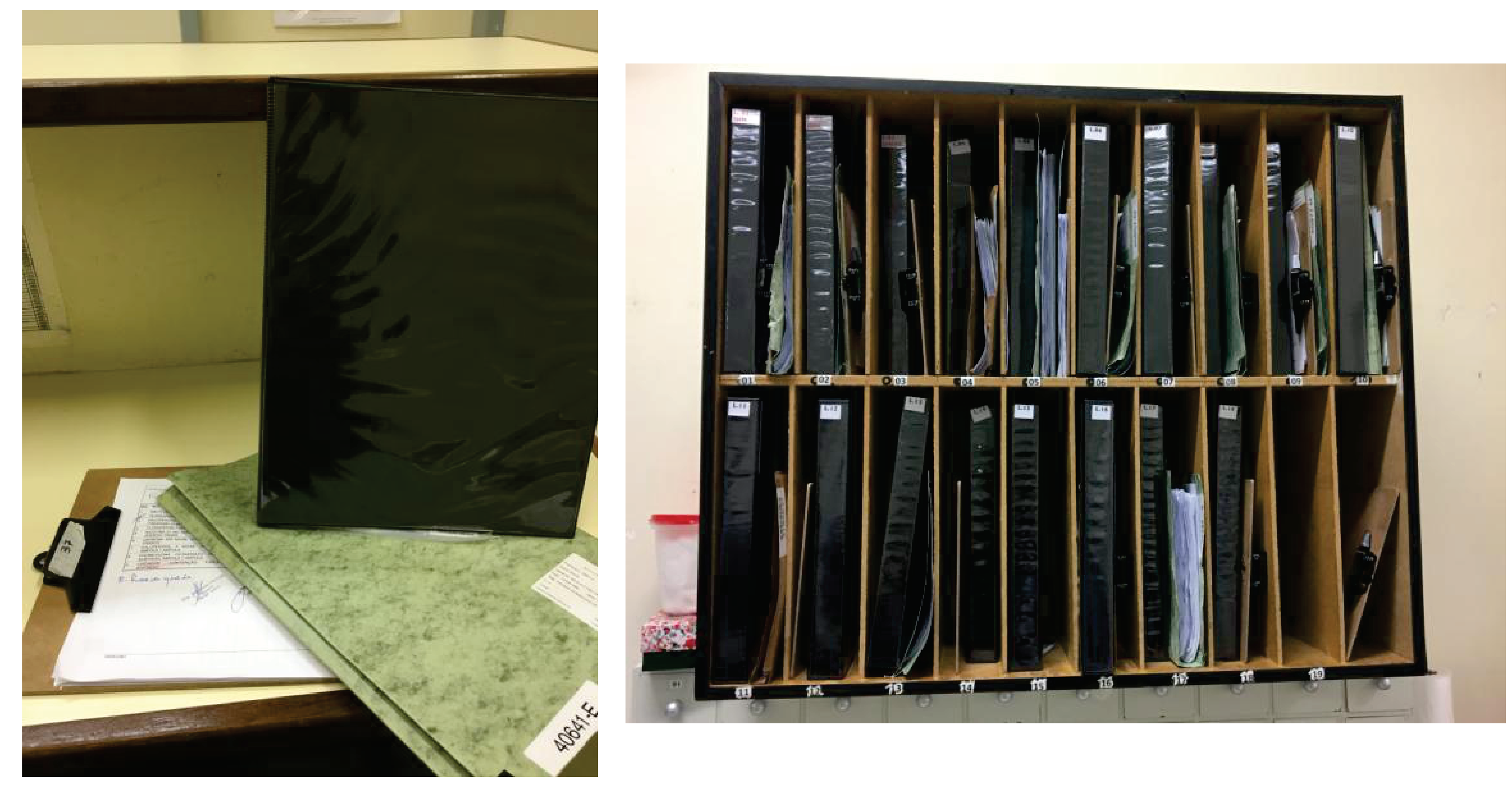